\title{
O DISCURSO LITERÁRIO DO INTELECTUAL PERIFÉRICO: ALGUMAS CONSIDERAÇÕES
}

\author{
CLEBER JOSÉ DE OLIVEIRA ${ }^{1}$ \\ Universidade Estadual de Mato Grosso do Sul-UEMS/Poslit-UNB
}

cleber101578@gmail.com

\begin{abstract}
Resumo. Nas últimas décadas o contexto sociopolítico brasileiro fez germinar uma manifestação literária autodenominada literatura periférica. Esta é quase que exclusivamente produzida por escritores oriundos de periferias urbanas dos grandes centros. Partindo desse pressuposto, o presente artigo busca descortinar como se manifestam as relações de representação $e$ autorrepresentação nessa forma de narrativa em detrimento ao modo utilizado pelos modernistas de representação das camadas menos abastadas. Entende-se aqui que essa nova manifestação literária colide com a chamada Tradição Modernista, onde autores como Graciliano Ramos, Clarice Lispector, João Cabral, Guimarães Rosa, entre outros, pertencentes a classes sociais altamente letradas produziram uma literatura que tomou para si a função de representar as classes marginalizadas (principalmente o nordestino, o sertanejo e o negro favelado). Fez isso por meio de um discurso alocado na boca de personagens subalternamente caracterizados tais como Fabiano, de Vidas Secas (1938); Macabéa, de A Hora da Estrela (1977); Severino, de Morte e Vida Severina (1955-6) e Riobaldo, de Grande Sertão: Veredas (1956). Com o espraiamento dessa tradição, a função que desempenhava seus intelectuais (o de representante das classes subalternas) fica vaga, e esse é o norteador da hipótese principal aqui levantada, a saber: essa função, que por muito tempo foi desempenhada pelos intelectuais modernista, é, agora, reivindicada e tomada por indivíduos oriundos das margens sociais, os intelectuais periféricos, porém, com diferentes intenções.
\end{abstract}

Palavras-chave: discurso literário; contemporaneidade; intelectual periférico; representação; autorrepresentação.

\begin{abstract}
In the last four decades the Brazilian sociopolitical context has generated a literary manifestation, self-described as peripheral literature. Almost exclusively produced by writers from urban outskirts of major centers. Based on this assumption, the present work seeks to unveil how they manifest themselves to the relations of representation and self-representation in this form of narrative, to the detriment of the mode of representation used by the modernists. It is understood here that this new literary manifestation collides with the so-called Modernist Tradition, where authors such as Graciliano Ramos, Clarice Lispector, João Cabral, Guimarães Rosa, among others, belonging to highly literate social classes produced a literature that took the
\end{abstract}

\footnotetext{
${ }^{1}$ Doutorando em Letras pela Universidade Nacional de Brasília-UNB.
} 
function of Represent the marginalized classes (mainly the northeastern, the sertanejo and the black favelado). He did this through a discourse in the mouth of subalternly characterized characters (possibly a consequence of non-literacy as soon as non-literacy), as Fabiano of Dry Lives (1938); Macabéa, from A Hora da Estrela (1977); Severino, of Death and Vida Severina (1955-6) and Riobaldo, of Grande Sertão: Veredas (1956). With the spread of this tradition, the function played by its intellectuals (the representative of the subaltern classes) is vague. This is the guiding principle of the main hypothesis raised here, namely: this function, which for a long time was performed by the modernist intellectuals, is now claimed and taken by individuals from the social margins (the marginal intellectual), but with different intentions. Keywords: literary discourse; contemporaneity; peripherical intellectual; representation; self-representation.

\title{
1. DIÁLOGOS E CONFRONTOS DE REPRESENTAÇÃO NA ESFERA LITERÁRIA BRASILEIRA
}

- O bicho, meu Deus, era um homem. Manuel Bandeira

\begin{abstract}
"Cala a boca, negro e pobre aqui não tem vez! Cala a boca!Cala a boca uma porra, agora agente fala, agora agente canta, e na moral agora agente escreve.

Ferréz
\end{abstract}

A contemporaneidade, inegavelmente, nos colocou diante de uma nova fórmula de se escrever literatura. Uma produção que não se restringe à narrativa de uma ficção, mas que esta emaranhada, consubstancia no enigmático universo que a legitima - a vida nas periferias. Essa nova estética (de)marca um - novo lócus literário que amparada em uma circunstância social, econômica e política que coloca em xeque muitas das teorias abordadas pelos estudos da Teoria Literária.

Para uma compreensão melhor de como se deu o surgimento e o desenvolvimento da estética literária periférica, é preciso ter claro que pré-existe uma tradição literária que por muito tempo tomou para si (no campo ficcional e ideológico) a tarefa de enunciar os desejos, os sonhos, as angústias e as esperanças das classes subalternas. Esses enunciadores, dos desejos alheios, não raro, são romancistas, poetas, cronistas e letristas, oriundos de classes sociais opostas a daqueles que figuram como protagonista em suas narrativas.

No Brasil, isso se deu, principalmente, a partir do início do século XX, com o advento do Modernismo. A respeito disso, Candido nos informa: 
a denominação de Modernismo abrange, em nossa literatura, três fatos intimamente ligados: Um movimento, uma estética e um período. $\mathrm{O}$ movimento surgiu em São Paulo com a famosa Semana da Arte Moderna, em 1922, e se ramificou depois pelo país, tendo como finalidade principal superar a literatura vigente, formada pelos restos do Naturalismo, do Parnasianismo e do Simbolismo. Correspondeu a ele uma teoria estética, nem sempre claramente delineada, e muito menos unificada, mas que visava, sobretudo, orientar e definir uma renovação, formulando em novos termos o conceito de literatura e de escritor. Estes fatos tiveram o seu momento mais dinâmico e agressivo até mais ou menos 1930, abrindo-se a partir daí uma nova etapa de maturação, cujo término se tem localizado cada vez mais no ano de 1945. (CANDIDO, 2000, p. 07)

Ademais, o Modernismo brasileiro foi além de um movimento artístico, um movimento ideológico engajado que buscou apresentar e valorizar a cultura popular nacional (CANDIDO 2006; BOSI 2013). É possível entrever isso no esforço empenhado por alguns dos principais autores modernista em retratar o modo de vida do indivíduo excluído, do sertanejo retirante e ainda denunciar a ausência do Estado brasileiro nas comunidades periféricas. Explicitaram também as desigualdades sociais historicamente impostas sobre esses indivíduos/grupos. De certa maneira, isso serviu para apresentar aos centros (São Paulo e Rio de Janeiro) as condições subumanas, principalmente no nordeste brasileiro, em que viviam uma grande parcela da população brasileira (e que até hoje vivem). Obras como Macunaíma (1928), de Mario de Andrade; O Quinze (1930), de Raquel de Queirós; Vidas Secas (1938), de Graciliano; Grande Sertão: veredas, de Guimarães Rosa; Morte e Vida Severina (1954-5), de João Cabral, isso para ficarmos em alguns exemplos, são emblemáticas para ilustrar o esquema literário de representação, a saber: um escritor de classe média alta, altamente letrado, que fala, nestes casos, por um pobre não alfabetizado consequentemente marginalizado (SPIVAK, 2010) que quase nunca figuram como prioridade nos planos do Estado.

Entendendo, agora, com Dalcastagné,

na história da literatura brasileira, a representação do "outro" atravessa diversos momentos: da idealização romântica dos índios ao herói sem nenhum caráter de Mário de Andrade, passamos ainda pelos malandros e prostitutas do cortiço de Aluísio Azevedo, os homossexuais de Adolfo Caminha, os sertanejos em luta descritos por Euclides da Cunha [...] um espaço bastante rico para a análise dessa representação é o regionalismo. Quase sempre vinculado a um projeto de constituição da identidade nacional, ele percorre escolas e séculos, esbarrando no cosmopolitismo dos modernistas, reagindo nos anos 1930, com o "ciclo do romance nordestino", e se dissolvendo na década de 1970, quando o Brasil se percebe um país majoritariamente urbano e sua literatura passa a se ocupar fundamentalmente com os problemas dos habitantes das cidades. (DALCASTAGNÉ, 2002, p. 39-40)

Este esquema de representar, como tema literário, a condição de exclusão a qual está inserida grande parte da população brasileira foi por muito tempo utilizado por vários intelectuais e, não raro, pelos intelectuais modernistas. Ainda que esta representação, num primeiro momento, seja permeada de "boas intenções", isso no sentido de denunciar e 
criticar a condição de invisibilidade em essa enorme parcela da população está inserida (que não raro é promovido pelo Estado e por grupos de poder), por outro lado, amordaçou e calou o desejo que por muito tempo tentou e tenta ecoar das bocas marginalizadas (SPIVAK, 2010). Esse desejo é o de poder se autorrepresentar, de poder falar por si, de firmar um lócus de enunciação de onde se possa reivindicar, a seu modo e com sua própria linguagem artística ou não artística, os direitos que por lei são assegurados a todos os indivíduos de uma sociedade.

É nesse cenário de conflito ideológico entre quem pode e quem não pode exercer o poder de fala na esfera pública, na luta entre implantação de dispositivos de cerceamento do discurso e a resistência a estes mecanismos (FOUCAULT, 2010; SPIVAK, 2010), que se manifesta intensamente a disputa de/pela representação. Considerando esse pressuposto, é possível dizer então que é em decorrência desta disputa que, na contemporaneidade, germina a estética periférica que, a meu ver, tem como suas principais características o lócus geográfico e de enunciação, a linguagem própria e o seu indivíduo produtor (que não raro esta na condição de excluído social).

Entendendo como excluídos todos os indivíduos e/ou comunidades que, de alguma forma, são subjugados socialmente por não figurarem como protagonista no mundo letrado acadêmico, no poder político e econômico, na produção cultural, isso porque há eficazes dispositivos de impedimento (FOUCAULT, 2010). Caso exemplar disso é Carolina Maria de Jesus (1974-1977), mulher negra, periférica e catadora de papel e que entre as décadas de 60 e 70, do século XX, escreve e publica as obras literárias Quarto de despejo diário de uma favelada e Diário de Bitita. Obras que por muito tempo estiveram excluídas da esfera dos bens simbólicos e da cultura, e que ainda não foram totalmente incorporadas à esfera cultural devido a certo ranço que insiste em permanecer em parte da sociedade brasileira.

O fazer artístico que ecoa das periferias para o centro. Esse deslocamento pode ser visto sob dois aspectos principais, a saber: o primeiro é o deslocamento do discurso, que sai da hegemonia que por décadas foi dos centros para também manifestar-se com força das margens onde, até então, não havia uma voz ativa. O segundo aspecto é o do poder de representação que forjou nessas comunidades uma espécie de rejeição aos representantes externos, ou seja, os que não são delas oriundos. Dessa maneira, começam a surgir vozes conscientes de seu papel social das próprias camadas marginalizadas.

Isso que estou chamando de vozes conscientes deve ser entendido como sendo os indivíduos oriundos das periferias urbanas marcadas pela violência no sentido mais amplo que esta palavra possa expressar, mas que ainda sim demonstram enorme consciência sociopolítica e cultural. Exemplo disso são os escritores, grupos de rap, ativistas, grafiteiros que surgem, em todo Brasil, questionando e denunciando a ausência do poder público e a condição às vezes subumanas vividas nessas periferias. São estes indivíduos e sua coletividade que produzem essa estética periférica, a qual sustento que seu marco inicial são as produções artísticas de Carolina Maria De Jesus. Não raro, esta estética está em constante diálogo de incorporação de outras manifestações artísticas oriundas também das periferias tais como o rap, o samba, o grafite, o reggae.

Possivelmente isso é pensado num plano de firmar um lócus de enunciação onde os alguns membros da mesma comunidade se constituem como porta-vozes dos anseios 
e angústias dos que sempre foram silenciados e, que estão em sua grande maioria nas periferias, nos guetos e nas favelas do sistema social. Com isso, e não por acaso, cria-se uma rejeição a representantes e mediadores externos que quase sempre estão vinculados a outras ideologias. Assim, sustento que escritores Paulo Lins, Sergio Vaz e Ferréz e rappers como Gog, Mano Brown, Emicida, entre tantos outros podem ser vistos como artífices dessa expressão literária periférica, herdeiros de Carolina Maria de Jesus. Seus textos estão ou querem estar comprometidos com uma espécie de projeto que tem como intuito principal à entrada de suas comunidades na esfera da autorrepresentação por meio do letramento cultural e consequentemente no da escrita literária, consolidando assim seu próprio lócus de enunciação, de onde falam e ouvem sua própria voz. Contudo, é sabido que no Brasil existem diversos dispositivos oficiais o vestibular é um deles, que vedam o acesso dessas comunidades ao mundo letrado, da cultura tradicional e dos bens de consumo. Porém com o advento da Internet e outros meios de comunicação (mas ainda não plenamente a do livro, artigo de luxo no em nosso país) alguns desses indivíduos se inseriram, ainda que a revelia do sistema, e a seu modo se letraram. Munidos, agora, com a tecnologia da palavra os grupos marginalizados reclamam sua participação efetiva nas decisões sociopolíticas e a partir disso tentam se "emancipar intelectualmente".

Essa emancipação se dá a partir do momento em que essas camadas, historicamente vistas como inferiores intelectualmente, perceberam que o baixo nível de letramento e de produção intelectual em que foram inseridos é uma das maneiras usadas, em nosso país, para se operar a divisão de classes (FOUCAULT, 2010; SPIVAK, 2010; DALCASTAGNÉ, 2012). Assim, assumir uma posição subversiva perante o Estado, produzir seu próprio discurso literário, artístico, é, sobretudo, uma forma de resistência aos séculos de exclusão social a que foram submetidos.

\section{SOBRE O INTELECTUAL: ALGUMAS CONSIDERAÇÕES}

Desde a segunda metade do século XIX, a figura do intelectual tem sido problematizada sob os mais variados enfoques. Atualmente, essa figura social continua sendo de definição complexa. Todavia, há uma característica que permeia a grande maioria dos conceitos tradicionais sobre o intelectual, a saber: a de que esta figura sempre esteve relacionada a ideias e a palavras, ferramentas essenciais para o desenvolvimento de sua atividade. Partindo desse pressuposto, traço um panorama teórico sobre os conceitos recorrentes de intelectual para entrever a possibilidade de um viés periférico de intelectual.

Para Antonio Gramsci (1982), todos os homens são intelectuais, poder-se-ia dizer então: mas nem todos os homens desempenham na sociedade a função de intelectual. Segundo o autor, cada grupo social cria seus próprios intelectuais. Podem ser chamados de orgânicos os intelectuais que devem ser constituídos pela educação técnica e devem participar da vida prática como construtores e organizadores permanentes, conscientes de sua função. Gramsci entende ainda que os intelectuais orgânicos são indivíduos que se implicam ativamente na sociedade, lutando constantemente para modificar as mentes e suas realidades sociais ainda que isso ocorra de modo inconsciente. Enquanto que os intelectuais tradicionais se caracterizam por considerarem a si mesmos como autônomos e independentes do grupo social existente por conta de sua continuidade histórica. 
Enfatizando sua afirmação, a de que todo ser humano é dotado de uma "função" intelectual, Gramsci explica:

quando se distingue entre intelectuais e não-intelectuais, faz-se referência, na realidade, tão-somente à imediata função social da categoria profissional dos intelectuais, isto é, leva-se em conta a direção sobre a qual incide o peso maior da atividade profissional específica, se na elaboração intelectual ou se no esforço muscular-nervoso. Isto significa que, se se pode falar de intelectuais, é impossível falar de nãointelectuais, porque não existem não-intelectuais. Não existe atividade humana da qual se possa excluir toda intervenção intelectual, não se pode separar o homo faber do homo sapiens.

E aponta ainda que, na modernidade,

o tipo tradicional e vulgarizado do intelectual é fornecido pelo literato, pelo filósofo, pelo artista. Por isso, os jornalistas — que crêem ser literatos, filósofos, artistas — crêem também ser os "verdadeiros" intelectuais. No mundo moderno, a educação técnica, estreitamente ligada ao trabalho industrial, mesmo ao mais primitivo e desqualificado, deve constituir a base do novo tipo de intelectual. (GRAMSCI, 1982, p. 7-8)

$\mathrm{Na}$ tentativa de descortinar algumas características do intelectual que produz a narrativa marginal, tomemos como base o conceito de Edward Said (2005), sobre o que é um intelectual e qual o seu papel na sociedade (é preciso marcar aqui que Said pondera sobre um conceito de intelectual, digamos, universal; o conceito de intelectual marginal que levanto neste trabalho se desenvolve ainda a título de hipótese). Vejamos suas ponderações.

O intelectual é um indivíduo com um papel público na sociedade [...] um ser dotado de uma vocação para representar, dar corpo e articular uma mensagem, um ponto de vista, uma atitude, filosofia ou opinião para e também por um público. Esse papel encerra uma certa agudeza, pois não pode ser desempenhado sem a consciência de ser alguém cuja função é levantar publicamente questões embaraçosas, confrontar ortodoxias e dogmas (mais do que produzi-los); isto é, alguém que não pode ser facilmente cooptado por governos ou corporações, e cuja razão de ser é representar todas as pessoas e todos os problemas que são sistematicamente esquecidos ou varridos para debaixo do tapete. Assim, o intelectual age com base em princípios universais: que todos os seres humanos têm direito de contar com os padrões de comportamento decentes quanto à liberdade e à justiça da parte dos poderes ou das nações do mundo, e que as violações deliberadas ou inadvertidas desses padrões têm de ser corajosamente denunciadas e combatidas. (SAID, 2005, p. 25-6; grifo meu)

Said aponta, em sua ponderação, o engajamento combativo que o intelectual deve ter pelas causas sociais/humanitárias que surgem a todo o momento na esfera pública. Contudo, isso parece ser um posicionamento utópico já que muitos intelectuais se inserem numa espécie de contradição ideológica ao defenderem grupos e Estados opressores. 
Em Sartre é possível enxergar a postura de alguém que se encontra inserido numa contradição, pois se vê dentro da mesma realidade da qual aqueles a quem defende estão inseridos e ao mesmo tempo está distante dela culturalmente e economicamente. Podemos enxergar isso sob a ótica de que todo intelectual vive dentro de um permanente conflito, pois, como intelectual (alguém que está longe de viver a realidade daqueles a que quer defender), entende que por muitas vezes sua voz não será ouvida e se for não será compreendida sem distorções, mas que, no entanto, não desiste e crê que por meio de sua intervenção algo possa ser mudado. Sobre isso, Sartre afirma que o intelectual é definido justamente por tal contradição.

O intelectual se caracteriza por não ter mandato de ninguém e por não ter recebido seu estatuto de nenhuma autoridade. [...] Ninguém o reivindica, ninguém o reconhece (nem o Estado, nem a elite-poder, nem os grupos de pressão, nem os aparelhos das classes exploradas, nem as massas); pode-se ser sensível ao que ele diz, mas não à sua existência [...] O intelectual é suprimido pela própria maneira em que se faz uso de seus produtos. (SARTRE, 1994, p. 32-3)

Michel Foucault também discute o conceito de intelectual. Em Microfisica do poder (1979), há importante texto sobre o assunto. Nele, Foucault anuncia a necessidade de aparecimento de uma nova forma de posicionamento do intelectual: não mais como aquele que dizia a verdade aos que ainda não a viam e em nome dos que não podiam dizêla. Mais do que um novo papel para o intelectual, trata-se de uma nova exigência, sob pena da figura do intelectual entrar em ocaso.

Ora, o que os intelectuais descobriram recentemente é que as massas não necessitam deles para saber; elas sabem perfeitamente, claramente, muito melhor do que eles; e elas o dizem muito bem. Mas existe um sistema de poder que barra, proíbe, invalida esse discurso e esse saber. Poder que não se encontra somente nas instâncias superiores da censura, mas que penetra muito profundamente, muito sutilmente em toda a trama da sociedade. Os próprios intelectuais fazem parte desse sistema de poder, a "ideia" de que eles são agentes da "consciência" e do discurso também faz parte desse sistema. O papel do intelectual não é mais o de se colocar "um pouco na frente ou um pouco de lado" para dizer a muda verdade de todos; é antes o de lutar contra as formas de poder exatamente onde ele é, ao mesmo tempo, o objeto e o instrumento; na ordem do saber, da "verdade", da "consciência". (FOUCAULT, 1979, p. 71)

Beatriz Sarlo, com um olhar atento frente às constantes mudanças da figura do intelectual e do seu papel social na contemporaneidade, pondera:

foram conselheiros de príncipes, de ditadores, de déspotas esclarecidos, de outros intelectuais convertidos em políticos, de políticos intelectuais e de políticos que tiveram pouco a ver com o mundo das ideias. Falaram ao Povo, à Nação, aos Desvalidos deste Mundo, às Raças oprimidas, às Minorias. Quando se dirigiram a tais interlocutores pensaram que estavam transferindo para eles uma verdade que tinham descoberto pelos próprios meios. Por isso, sentiram-se Representantes, homens e mulheres que tomavam a palavra em nome de outros homens e mulheres. E, por isso, acreditaram que essa representação, esse dizer, o 
que os outros não podem nem sabem dizer, era um de seus deveres: o dever do saber. Deviam então libertar os outros das travas que lhe impediam de pensar e agir; enquanto isso, enquanto essa nova consciência não se impusesse a seus futuros portadores, falaram em nome deles. (SARLO, 2000, p. 160-1)

Para Sarlo, a contemporaneidade põe em crise o papel clássico do intelectual que ela mesma descreve no trecho acima. Sendo assim, na medida em que a contemporaneidade avançou sobre a sociedade com suas novas formas e fórmulas de relações sociais, se foram abrindo espaço para o aparecimento de outros meios de intervenção na vida pública. Com isso, o tipo clássico de intelectual, perde espaço e em parte o poder de falar em nome do outro, especialmente, pelas camadas que até então eram cerceadas de voz (possivelmente é dessa lacuna aberta que surja a figura de uma figura intelectualizada aos moldes dessas camadas asfixiadas de voz). A massa, o povo, não precisa deles para saber, não necessita deles para falar. Isso abriu caminho, sobretudo, para novos agentes sociais e para novas perspectivas de atuação na esfera socioeconômica. Os ideais do intelectual clássico foram colocados em cheque, por, dentre outros, não se realizar de fato após séculos de promessas. Diz Sarlo:

As sociedades que surgem da modernidade tardia (isso que chamamos taquigraficamente de "pós-modernidade") estão longe de realizar um ideal igualitarista e democrático [...] Se nos países centrais a riqueza viabiliza políticas de compensação por parte do Estado, e os movimentos sociais aí intervêm na esfera pública, nos países periféricos a explosão do fim do século XX mostra, mais que a diversidade cultural e social, o intolerável contraste entre a miséria e a riqueza. (SARLO, 2000, p. 164-5)

À luz de Foucault e Sarlo, o próprio papel do intelectual parece fazer parte do "sistema" de manutenção destes contrastes. Aquela figura responsável por representar os oprimidos era ele próprio, inconscientemente, instrumento de um sistema de manutenção da opressão. Foucault é um dos primeiros a denunciar isso. E Sarlo, na esteira de pensadores como Foucault, também acusa esse impasse.

Contudo, ela não abandona a crença na importância do intelectual. Sarlo aponta que na contemporaneidade surge a necessidade de se retomar algumas das funções que eram inerentes ao intelectual clássico (acredito que algumas dessas funções estejam sendo (re)tomadas pela estética periférica e seus intelectuais quando adotam um posicionamento de confronto frente aos grupos de poder hegemônico, isso por meio de um discurso artístico crítico-subversivo).

A figura do intelectual (artista, filósofo, pensador), tal como criada na modernidade clássica, entrou em seu ocaso. Algumas das funções que essa figura considerava suas, porém, continuam a ser reclamadas por uma realidade que mudou e que, portanto já não aceita legisladores nem profetas como guias, mas não tanto a ponto de tornar inútil o que foi o eixo da prática intelectual nos últimos dois séculos: a crítica daquilo que existe, o espírito livre e anticonformista, o destemor perante os poderosos, o sentido de solidariedade com as vítimas. (SARLO, 2000, p. 165) 
Neste panorama de ponderações sobre a figura do intelectual, me parece que os autores comungam de uma visão em comum, a de que o intelectual é um indivíduo que deve se fazer presente na vida pública contestando, denunciando e revidando às implantações de dispositivos sociais que visam dar manutenção as desigualdades e injustiças que afetam grande parte do corpo social. Atitude e postura que, atualmente, é vista por muitos como sendo algo que está na esfera da utopia. Contudo, na minha ótica, esta atitude e postura faz parte do cotidiano dos ativistas culturais, poetas, escritores que são oriundos das periferias. Ou seja, estes indivíduos exercem, a seu modo e com sua linguagem, algumas das funções que por muito tempo ficou sob o domínio dos intelectuais tradicionais. Fazem isso por meio de sua produção artística (rap, poesia, romance, música, saraus) que se aglutinam na estética periférica.

De modo geral, as obras literárias periféricas parecem estar inseridas dentro de um projeto de conscientização de suas comunidades, isso no sentido em que explicitam e denunciam os procedimentos, os dispositivos sociais de exclusão que estão presente na sociedade contemporânea. Mais que isso, são reflexos das mudanças sociais ocorridas em nosso país, no mínimo, nas últimas cinco décadas, mas agora vistas por uma outra perspectiva a de um indivíduo nativo dos guetos, das favelas, o qual denomino de intelectual periférico. Suas narrativas se caracterizam por ser um híbrido quase sempre de relato e ficção, de experiências vividas, vistas e inventadas nos guetos suburbanos. Essa espécie (nova?) de intelectual tomou de assalto o acesso à alfabetização e ao letramento que sempre lhe foi, de uma forma ou de outra, negado. Faz-se necessário, aqui o seguinte questionamento: será que juntamente com o assalto a alfabetização e ao letramento veio também à tomada de consciência no sentido de assumir a função de representante e portavoz de sua comunidade?

Pode-se dizer que diferentemente dos intelectuais tradicionais inserido no projeto modernista de nação (esse projeto foi uma tentativa de atenuação das diferenças sociais e culturais e de aproximação entre povo e elite, e que se mostrou ideológico), o intelectual periférico caracteriza-se justamente pela descrença nesse projeto e em outros semelhantes, pois perante a realidade que o cerca (e a todos nós também): capitalismo doentio, a falta de paz e a vida mecanizada, já não acredita em uma coesão social entre elite e favela, nem em qualquer utopia equivalente. Esta descrença se dá também pelo motivo de a vida contemporânea ter trazido consigo uma espécie de distanciamento e esfriamento nas relações sócio-humanas, uma espécie de liquides (BAUMAM, 2000).

Nesse sentido, apresento como exemplo de intelectual periférico, a partir da análise de alguns de seus textos, o escritor, ativista cultural, poeta, rapper e fundador da Idasul, Reginaldo da Silva Ferreira, mais conhecido como Ferréz. Nascido e morador do Capão Redondo, periferia da cidade de São Paulo. Ferréz será tomado aqui como uma espécie de metonímia (a parte pelo todo) do viés de intelectual periférico, ou seja, sua figura remonta a outras figuras tais como Sergio Vaz, Sacolinha, Gog, Racionais MCs, Emicida, Paulo Lins, Conceição Evaristo - todos herdeiros de Carolina Maria de Jesus - que também são oriundos e habitantes dos quartos de despejos da vida social brasileira, e que comungam do projeto de autorrepresentação dos indivíduos excluídos vinculado à estética periférica.

Para tanto, faço o seguinte questionamento em que medida Ferréz (e estes outros) pode $(\mathrm{m})$ ser caracterizado como um intelectual periférico? Tendo em vista o conceito de intelectual, ainda que clássico, apresentado por Said, pode-se dizer que Ferréz apresenta 
algumas características desse conceito, pelo menos no que diz respeito ao ser público e defender as camadas populares, das quais é oriundo. Ademais, não há como desvinculá-lo de outras duas características à sua origem e aos temas de suas narrativas. Isso o faz ganhar na condição de intelectual um adjetivo - periférico. No entanto, para sustentar, com autoridade. que este escritor é um intelectual periférico traço uma análise mais aprofundada em seus textos justamente no sentido de descortinar as ideologias ali inseridas e se realmente este autor se configura como uma espécie de representante e/ou porta-voz de sua comunidade e ele próprio se reconhece como tal. Vejamos o texto a seguir, intitulado "Rio de Sangue".

Fique a vontade para entrar no mundo adulto da violência gratuita, do grande plano de manipulação que joga contra o revoltado e tão cansado povo brasileiro, da covardia sem limites, do esfacelamento de famílias, do rio de sangue temperado com baixa estima, e das vielas cheias de corpos cansados demais para entender a difícil engrenagem de uma sociedade fantoche [...] não culpai meu pai esse povo que não sabe votar [...] a verdade é que o Estado está organizado para não deixar que a elite perca poder econômico e político, estão todos preparados para boicotar qualquer tentativa de crescimento da classe tida por eles como mais baixa, que na real somos nós. (FERRÉZ, 2005, p. 57)

O discurso literário é forte e marcante. Em termos estéticos é marcado pela ironia, rebeldia e contestação, que se manifesta, sobretudo, no teor "sujo" de sua linguagem (academicamente incorreta), repleta de gírias, revolta e denuncia. O narrador convida o leitor a conhecer o seu mundo, os seus, a sua realidade. Tenta deixar claro que não é alguém tão alienado quanto os outros (essa é uma característica do conceito de intelectual proposto por Sartre, a da não alienação), isso fica evidente quando reconhece que a grande maioria dos seus parece não entender o funcionamento da máquina social em que estão inseridos "vielas cheias de corpos cansados demais para entender a dificil engrenagem de uma sociedade fantoche". Compreende que eles não são culpados pelo caos instalado "não culpai meu pai esse povo que não sabe votar". Assim, tenta evidenciar a alienação em que estão mergulhados e denunciar o descaso com que são tratados pelos grupos de poder e pelo Estado. Demonstra sua capacidade de construir o próprio pensamento, por meio de um discurso forte e realista, consolidando assim a autoridade de se autorrepresentar. O posicionamento crítico assumido pelo autor e a sua busca por uma autorrepresentação vem ao encontro das ponderações feitas por Said anteriormente sobre o papel do intelectual contemporâneo.

Continuemos no fluxo da análise, a partir de um outro trecho.

Eu quero ter o belo prazer subversivo de escrever minha literatura periférica, eu quero ser preso, mas por porte ilegal de inteligência, antigamente quilombos hoje periferia, o zumbi zumbizando a elite mesquinha, Záfrica Brasil um só por todos nós, somos monjolos, somos branquindiafros, somos Clãnordestino, a peste negra, somos Racionais, somos Negro Drama, e minha posse é mente zulu. (FERRÉZ, 2005, p. 57)

Neste trecho, o autor se reconhece como produtor de literatura periférica. Tem a consciência que a inteligência para sujeitos oriundos de favelas é um crime aos olhos dos grupos de poder. Promove comparações nas quais sugere que no sistema social brasileiro tudo continua igual (isso em relação ao lugar imposto aos excluídos historicamente) apesar 
de da mudança na nomenclatura "antigamente quilombo, hoje periferia". Na mesma medida, igual também permanece o pensamento subversivo, em relação ao discurso de poder das elites, e a força de resistência desses indivíduos, porém agora com a mesma arma do opressor - a inteligência e a palavra escrita, a literatura - "eu quero ter o belo prazer subversivo de escrever minha literatura marginal, eu quero ser preso, mas por porte ilegal de inteligência", com isso busca uma espécie de parelhamento nas relações de poder baseadas na horizontalização dessas relações onde os anseios das periferias figuraria também nos projetos do Estado.

[...] Os tidos revolucionários que conheci, se deram bem resolveram seus problemas, alguns até foram eleitos, falam nos palanques com mais energia, e citam exemplos de sofrimento que eu mesmo passo todos os dias [...] Não temos medo nem raiva do poder, mas temos nojo "dessa" forma de poder, a forma que o jeitinho brasileiro consagrou e hoje faz milhões de pessoas choraram lágrimas de sangue [...]não é pelas mortes de pobres nos morros que a elite ta reclamando, que as apresentadoras loiras tão chorando, não é pelo preto, nem pelo pobre, é por seus próprios rabos, a coisa desceu pro asfalto, o sangue chegou perto, quantos avisos, quantos pedidos de socorro, mas a criança cresceu, sem nada, nada. (FERRÉZ, 2005, 57-8; grifo meu)

Como se vê também neste trecho, a estética periférica se caracteriza por um esforço para demonstrar que ela (a narrativa) se desenvolve na substância da experiência vivida, vide grifo. Nesse sentido, pode-se dizer que este indivíduo mesmo sendo oprimido e subalternizado, esforça-se para falar por si e pela comunidade a que pertence. Note-se que o narrador tece uma forte crítica aos discursos dissimulados e vazios pronunciados por apresentadoras loiras, principalmente, de TV. Constata ainda que fazem isso não por empatia aos despossuídos e favelados, mas sim por uma espécie de autoproteção, por medo.

$\mathrm{Na}$ estética periférica falar de si é falar do outro, isso devido ao sentimento de pertença que permeia toda essa produção. Tudo isso se constrói na tentativa de combater, as relações sociais verticalizadas impostas pelas elites dominantes que em geral são detentoras dos meios de produção e informação. De subverter e rasurar o discurso do poder. De se colocar como sujeito enunciador capaz de fazer escolhas, que não raro culminam na descentralização do discurso de poder hegemônico.

Como foi possível entrever nas análises, Ferréz está no front de/da batalha sociopolítica pelo poder de falar por si, pela sua autonomia: cala a boca, negro e pobre aqui não tem vez! Cala a boca! Cala a boca uma porra, agora agente fala, agora agente canta, e na moral agora agente escreve. Com essa postura consciente e combativa o autor desempenha sim o papel de intelectual periférico ao atuar na esfera pública.

Assim, o fenômeno artístico periférico e os intelectuais surgidos daí tomam fôlego contemporaneamente porque provocaram uma fissura, por onde respiram e ecoa suas vozes, no sistema sociopolítico-cultura brasileiro. Isso evidência a característica contemporânea de deslocamento do discurso artístico que por muito tempo emanou apenas dos centros para as margens, mas que agora ecoa também das periferias para o centro. É preciso considerar também que a redemocratização do país, nos anos 90, tornou 
o terreno sociocultural brasileiro fértil e propício ao surgimento de novas formas e manifestações sócio-artísticas engajadas.

\section{CONSIDERAÇÕES FINAIS}

As ponderações feitas ao longo deste artigo se desenvolveram no sentido de lançar luz sobre os discursos de representação e autorrepresentação nas narrativas modernistas e nessa recente estética da literatura periférica. Além disso, expus por meio de algumas analises textuais que Ferréz possui algumas características que o configura e o legitima como sendo um intelectual periférico devido sua origem, sua arte literária, o estilo na linguagem, e o seu lócus enunciativo. Entrevi também aspectos do projeto de representação dos modernistas e a busca da autorrepresentação literatura periférica contemporânea. Uma continuidade entre ambas se deu no sentido de que ambas estão fora dos grandes circuitos editoriais. Uma descontinuidade que se evidenciou foi que há um maior engajamento por parte dos escritores intelectuais de literatura periférica contemporânea num projeto ideológico que busca por meio do mutirão a afirmação de sua identidade social (entenda-se mutirão como sendo o esforço comum entre escritores, poetas-MCs e grafiteiros de comunidades de periferia em prol de um mesmo ideal).

Não raro, em tempos como este em que vivemos, veremos cada vez mais discursos engajados e manifestações de cunho sociopolítico promovidas por comunidades que historicamente foram e são cerceadas de seus direitos básicos como educação e trabalho, à cidadania plena. Assim sendo, produzirão, a seu modo, porta-vozes, representantes e mediadores que estejam engajados com suas causas. Desse modo, acredito que a figura do intelectual periférico se fortalecerá desde que não se torne este um manipulador ou carrasco de sua própria comunidade.

Por fim, a título de pesquisa é preciso que se olhe com mais atenção para essa manifestação literária, por isso artística, que apresenta a capacidade de quebrar paradigmas tanto no campo social como no intelectual, pois já não dá mais para ignorarmos a existência desse lócus, nem tapar os ouvidos para a voz que ecoa do mesmo.

\section{REFÊRENCIAS}

BAKHTIN, Mikhail. Estética da criação verbal. São Paulo: Martins Fontes, 2011.

Marxismo e filosofia da linguagem: problemas fundamentais do método sociológico na ciência da língua. 10a . ed. São Paulo: Hucitec, 2004.

BOSI, A. História Concisa da Literatura Brasileira. 49a . ed. São Paulo: Cultrix 2013.

CANDIDO, Antonio. Formação da Literatura Brasileira: momentos decisivos. São Paulo; Rio de Janeiro: FAPESP; Ouro sobre Azul, 2009.

. A Revolução de 1930 e a Cultura. Em: A educação pela noite e outros ensaios. São Paulo: Ática, 2006. 
. Ficção e confissão: ensaios sobre Graciliano Ramos. $3^{\text {a }}$. ed. Rio de Janeiro: FAPESP; Ouro sobre Azul, 2006.

Brasil, 2001.

Presença da Literatura Brasileira: história e antologia. Rio de Janeiro: Bertrand

Literatura e sociedade. $8^{\text {a }}$. ed. São Paulo: T.A. Queiroz; Publifolha, 2000.

CURY, M. Zilda Ferreira; WALTY, Ivete Lara Camargos (Orgs.). Intelectuais e vida pública: migrações e mediações. Belo Horizonte: Ed. da UFMG/FALE, 2008.

DALCASTAGNE, Regina. Literatura brasileira contemporânea: um território contestado. Vinhedo: Ed. Horizonte, 2012.

- Uma voz ao sol: representação e legitimidade na narrativa brasileira contemporânea. Estudos de Literatura Brasileira Contemporânea, Brasília, 33-87, julho/agosto de 2002.

FERRÉZ: Cronista de um tempo ruim. São Paulo: Literatura Marginal, 2009.

Literatura marginal. São Paulo: Agir, 2005.

Ninguém é Inocente em São Paulo. São Paulo: Objetiva, 2006.

FOUCAULT, Michel. Microfísica do poder. Rio de Janeiro: Graal, 1999.

A Ordem do Discurso. São Paulo: Edições Loyola, 1996.

GRAMSCI, Antonio. Os intelectuais e a organização da cultura. Rio de Janeiro: Civilização Brasileira, 1995.

HALL, Stuart. A identidade cultural na pós-modernidade. $2^{\mathrm{a}}$. ed. Rio de Janeiro: DP\&A, 1998.

SAID, Edward W. Representações do intelectual: as conferências Reith de 1993. São Paulo: Companhia das Letras, 2005.

SARLO, Beatriz. Cenas da vida pós-moderna. Rio de Janeiro: UFRJ, 2000.

SPIVAK, Gayatri C. Pode o subalterno falar? Belo Horizonte: Ed. da UFMG, 2010.

Artigo recebido em: agosto de 2017.

Aprovado e revisado em: fevereiro de 2018.

Publicado em: maio de 2018. 


\section{Para citar este texto:}

OLIVEIRA, Cleber José de. O discurso literário do intelectual periférico: algumas considerações. Entremeios [Revista de Estudos do Discurso, ISSN 2179-3514, on-line, www.entremeios.inf.br], Seção Temática [Discurso, arte e literatura - Parte I], Programa de Pós-Graduação em Ciências da Linguagem (PPGCL), Universidade do Vale do Sapucaí (UNIVÁS), Pouso Alegre (MG), vol. 16, p. 245-258, jan. - jun. 2018.

DOI: http://dx.doi.org/10.20337/ISSN2179-3514revistaENTREMEIOSvol16pagina245a258 